\title{
Radiation therapy's efficacy on tongue cancer: a population-based survival analysis
}

This article was published in the following Dove Press journal: OncoTargets and Therapy

\section{Yu Zhu' \\ Chengmao Zhou ${ }^{2}$ \\ Qixiong $\mathrm{He}^{2}$}

'Department of Nursing, Zhaoqing Medical College, ${ }^{2}$ Department of Clinical Medicine, Zhaoqing Medical College, Zhaoqing 526020, People's Republic of China
Correspondence: Chengmao Zhou; Qixiong $\mathrm{He}$

Zhaoqing Medical College, No 6 Xijiangnan Road, Zhaoqing 526020, People's Republic of China

Tel +86 I87 7675 I8I6;

+86 I38 27576603

Email zhouchengmaol87@foxmail.com; heqixiong187@|26.com
Objective: To identify survival outcomes for patients with oral tongue cancer and the effects of different prognostic factors on survival.

Methods: A study was performed with the Surveillance, Epidemiology, and End Results database to confirm whether survival improved in patients who had received radiation therapy along with surgery compared with others who had received surgery alone.

Results: A total of 9,474 patients were included as respondents in the study. Of the group, 2,759 patients had been treated by surgery along with radiotherapy, while 6,714 just had received only surgery. The survival was higher in patients who had been treated by both surgery and radiotherapy. Moreover, old age $(P<0.001)$, being black $(P<0.001)$, distant stage $(P<0.001)$, first malignant primary indicator $(P<0.001)$, being unmarried $(P<0.001)$, and surgery only $(P<0.001)$ were confirmed as significant risk factors associated with low survival rates. Age 50 years and above (hazard ratio: $1.712,95 \%$ CI: 1.550-1.890) was also a significant risk factor. Nevertheless, grade and sex were not independent risk factors. The multivariate model also showed that being black, distant stage, age below 50 years, sex, being unmarried, and surgery were found to be associated with low survival rates $(P<0.001)$.

Conclusion: Of the patients with tongue cancer, the group treated by both radiation and surgery had better prognosis than the group that had received surgery only. Also, survival showed no difference in terms of sex among the total tongue cancer population, whereas prognosis was found to differ between two genders in the group that had received both radiation therapy and surgery. Nonetheless, grade was not a risk factor for patients with tongue cancer.

Keywords: SEER, tongue cancer, surgery, survival, radiation

\section{Introduction}

Tongue cancer accounts for $30 \%-50 \%$ of oral cancers. The frontal two-thirds of the tongue (with the circumvallate papilla as the boundary) is where the tongue can move. Cancer in this region is considered carcinoma of tongue. Cancer on the posterior third tongue is referred to as base of tongue cancer. The pathogenesis of tongue carcinoma is related to several factors such as poor oral hygiene, alcoholism, and heavy smoking. ${ }^{1}$

The surgical removal of primary tumors through regional lymph nodal clearance is a preferred therapeutic option for tongue cancer. However, it cannot be done if the primary tumor with clinically negative neck nodes is thinner than $2 \mathrm{~mm}$ based on postoperative examination of the neck. Radiation therapy was typically performed for advanced tumors, and the survival rates of patients with stage I and II deep tongue cancer were not impacted by postoperative radiation therapy. ${ }^{2}$ Postoperative radiation therapy was however effective for improving locoregional control rates, but did not improve overall survival rates. ${ }^{3}$ 
At present, no survival data are available for tongue cancer or for long-term locoregional control of the disease. Thus, there is a dearth of pertinent evidence, and the benefits of radiation and surgery for tongue cancer remain controversial. Therefore, this study was performed to assess whether the survival of patients who receive both surgery and radiation therapy is better than those treated by surgery alone. The study is based on the Surveillance, Epidemiology, and End Results (SEER) database.

\section{Materials and methods}

This study received ethics committee approval from Zhaoqing Medical College. The SEER Cancer Statistics Review (http://seer.cancer.gov/data/citation.html) is an annual report on the latest statistics about cancer mortality, prevalence, incidence, survival, and lifetime risk. It is published by the Data Analysis and Interpretation Branch of the National Cancer Institute, USA. At present, this database is composed of 18 population-based cancer registries. The SEER data is deidentified.

Patients diagnosed with tongue cancer between 2005 and 2008 (inclusive) were searched with SEER-stat (SEER*Stat Version 8.3.4, National Institute of Health, Bethesda, MD, USA). Histologically, only patients with tongue cancer $(8070 / 3,8071 / 3,8072 / 3,8073 / 3,8074 / 3,8075 / 3)$ were included in this study. Patients whose radiotherapy, grade, race, stage, and survival months were unknown were excluded. Patients' marital status, year of diagnosis, sex, stage, age, race, and survival time were extracted from the aforementioned database. Patients' radiation histories were recorded in the database at the time of diagnosis.

When necessary, patients' baseline characteristics were compared by performing a chi-squared test. Tongue cancer mortality was compared across groups with the KaplanMeier method, and the risk factors that influenced the survival of these patients were analyzed by multivariate Cox regression models. All statistical analyses were conducted with SPSS (version 20.0, IBM Corporation, Armonk, NY, USA). The differences were deemed statistically significant if the two-sided $P$-value was below 0.05 .

\section{Results}

A total of 9,474 patients diagnosed with tongue cancer between 2005 and 2008 (inclusive) were included as respondents in the study. Patient characteristics are shown in Table 1 . In this study, 2,759 patients were treated by surgery and radiotherapy, while 6,714 patients received only surgery. On average, the patients who had received both surgery and radiotherapy were younger than those treated by surgery alone $(P<0.001)$. There was also a higher percentage of whites. Both groups showed similar results for year of diagnosis.

Survival rates were higher among patients treated by both surgery and radiotherapy, as shown in Figure 1. Moreover, old age $(P<0.001)$, being black $(P<0.001)$, distant stage $(P<0.001)$, first malignant primary indicator $(P<0.001)$, not married $(P<0.001)$, and surgery only $(P<0.001)$ were confirmed as significant risk factors associated with poor survival, as indicated from univariate analysis and Cox regression. Age below 50 years (hazard ratio [HR]: 1.712, 95\% confidence interval [CI]: 1.550-1.890) was also a significant risk factor. Nevertheless, grade and sex were not independent risk factors (Table 2).

\section{Analysis of subgroups for evaluating effects of surgery and radiotherapy}

The multivariate model identified black, distant stage, age under 50 years, sex, being unmarried, and surgery as associated with poor survival $(P<0.001)$. Nonetheless, year of diagnosis and grade were not independent risk factors, as shown in Table 3.

\section{Discussion}

As a common form of head/neck cancer, tongue cancer is the most common form of oral cavity cancers. Surgical reconstruction techniques have improved, and the percentage of tongue cancer patients treated by surgery has increased steadily since $1980 .{ }^{4,5}$ Nevertheless, radiotherapy remains important in managing tongue carcinoma, owing to its better functional and aesthetic results. ${ }^{6}$ The data for this group suggested that the 5-year survival rate was 52.5\% among patients treated only by surgery, and $56.0 \%$ among patients who had received both radiotherapy and surgery. According to statistical analysis, therapeutic effects were better for the group treated by both radiotherapy and surgery than for patients treated by surgery alone. This is perhaps because the radiotherapy kills subclinical lesions and some tumor cells within targets while reducing local recurrence and distant metastasis. Thus, an ideal therapy option should be chosen clinically. The optimal treatment plan should be collaboratively designed by physicians from both radiotherapy and oral surgery departments, in order to improve local control rates and survival.

Likewise, Maochang et $\mathrm{al}^{7}$ have reported a 5-year survival rate of $31.03 \%$ among patients receiving surgery only, but as high as $68.08 \%$ among patients receiving combined 
Table I Baseline demographic and tumor characteristics of patients in SEER database

\begin{tabular}{|c|c|c|c|c|}
\hline Variables & Total & Surgery + radiotherapy & Surgery only total & P-value \\
\hline Year of diagnosis & & & & 0.661 \\
\hline $2005-2006$ & 4,444 & $\mathrm{I}, 304$ & 3,140 & \\
\hline 2007-2008 & 5,029 & $\mathrm{I}, 455$ & 3,574 & \\
\hline Sex & & & & $<0.001$ \\
\hline Male & 6,578 & 2,019 & 4,559 & \\
\hline Female & 2,895 & 740 & 2,155 & \\
\hline Marital status & & & & $<0.001$ \\
\hline Not married & 3,776 & 992 & 2,784 & \\
\hline Married & 5,136 & $\mathrm{I}, 677$ & 3,459 & \\
\hline Unknown & 561 & 90 & 471 & \\
\hline Race & & & & $<0.001$ \\
\hline White & 8,171 & 2,451 & 5,720 & \\
\hline Black & 696 & 149 & 547 & \\
\hline Other & 537 & 147 & 390 & \\
\hline Unknown & 69 & 12 & 57 & \\
\hline Age (years) & & & & $<0.001$ \\
\hline$\leq 50$ & 1,685 & 584 & 1,101 & \\
\hline$>50$ & 7,788 & 2,175 & 5,613 & \\
\hline Summary stage 2000 (1998+) & & & & $<0.001$ \\
\hline Distant & I,499 & 449 & $\mathrm{I}, 050$ & \\
\hline Regional & 4,265 & $\mathrm{I}, 767$ & 2,498 & \\
\hline Localized & 3,343 & 507 & 2,836 & \\
\hline Unknown/unstage & 366 & 36 & 330 & \\
\hline First malignant primary indicator & & & & $<0.001$ \\
\hline No & $\mathrm{I}, 754$ & 369 & $\mathrm{I}, 385$ & \\
\hline Yes & 7,719 & 2,390 & 6,714 & \\
\hline Grade & & & & $<0.001$ \\
\hline Well differentiated & 1,316 & 206 & 1,110 & \\
\hline Moderately differentiated & 3,893 & $\mathrm{I}, 144$ & 2,749 & \\
\hline Poorly differentiated & 2,457 & 918 & 1,539 & \\
\hline Undifferentiated & 58 & 26 & 32 & \\
\hline Unknown & 1,749 & 465 & I,284 & \\
\hline
\end{tabular}

Abbreviation: SEER, Surveillance, Epidemiology, and End Results.

treatment. This study suggested that the better therapeutic effects were associated with early postoperative therapy and the termination of subclinical legions. It was more effective to perform a postoperative therapy every 2 weeks. Since blood did not circulate well in tumor cells remaining after surgery and the cells became less sensitive to radiation, radiotherapy should be performed and dosages should be increased as early as possible.

Local recurrence is a major cause of treatment failure in tongue cancer. An ideal option for radiotherapy is combined treatment with external radiation and interstitial brachytherapy. This may significantly improve local control and survival rates, preserve the appearance of the tongue, and maintain its functions for chewing, swallowing, and pronunciation, thus improving patient survival rates. ${ }^{8}$ According to a report by the Shanghai Medical University Oncology Hospital, 123 cases with early-stage squamous cell carcinoma of the frontal oral tongue that moved were studied, and then treated by external radiation and interstitial therapy with radium needles. ${ }^{9}$ Among these patients, the 5- and 10-year survival rates at stages I and II were 92.3\% (24/26), 92.3\% (24/26), 80.4\% (78/97), and 71.1\% (69/97), respectively. Of patients who survived 10 years of follow-up visits, $96.8 \%$ (90/93) showed normal tongue function, and 94.6\% (88/93) 


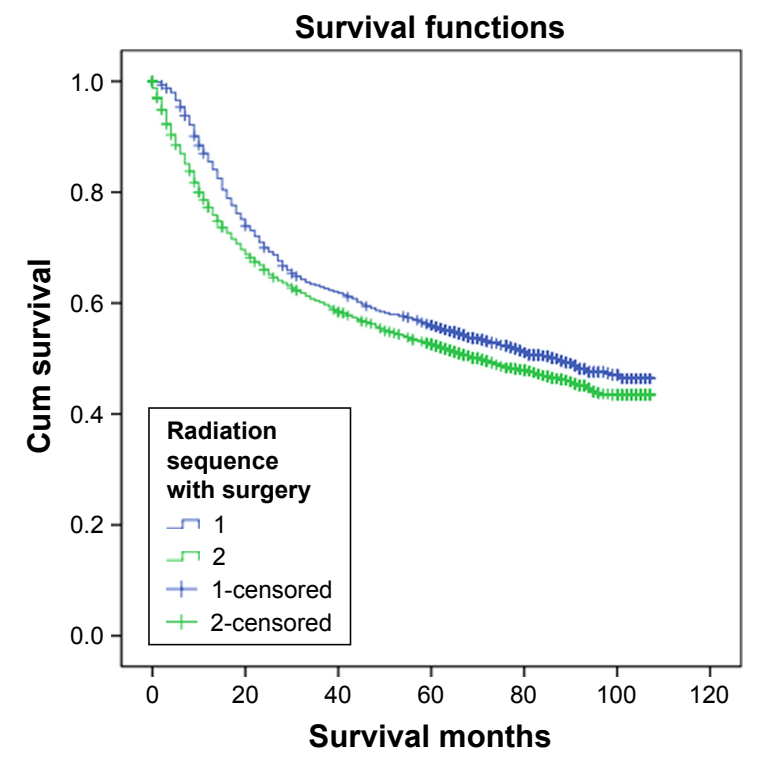

Figure I Survival curves for tongue cancer patients according to radiation therapies for tongue cancer with or without surgery.

Notes: $\chi^{2}=14.544, P<0.0001$. I: both surgery and radiotherapy; 2 : radiotherapy.

could take part in normal work. Therefore, combined treatment by appropriate external and interstitial radiation was an optional optimal therapy for patients with recurrent or advanced tongue cancer. The treatment of lymph nodes in the neck section had considerable impact upon prognosis. It was also reported that the failure rate was only $9 \%$ in patients who had received DT40-50 Gy preventive radiotherapy on the neck, and as high as $44 \%$ in others who had not been treated by radiotherapy. ${ }^{10}$

This study also suggested that for blacks and the elderly, both the summary stage 2000 (1998+) and the first malignant primary indicator were risk factors for the prognosis of tongue cancer. Men and women exhibited no difference in survival rates among the total tongue cancer population, whereas women's tongue cancer prognosis was worse than men's in the group that had received surgery and radiotherapy. However, grade was not a risk factor for the total tongue cancer population, nor was it a risk factor for patients who had been treated by surgery in combination with radiotherapy. Age was also reported to be a factor influencing tongue cancer treatment. ${ }^{11}$

Hence, patients that had received both radiotherapy and surgery for tongue cancer outperformed those who had been treated by surgery alone. Additionally, the survival rate was the same between the sexes among the total tongue cancer population. However, differences between the sexes did exist in tongue cancer prognosis for patients who had been treated

Table 2 Univariate and multivariate survival analysis of overall survival in the SEER database for evaluating the influence of receiving radiation and surgery treatment for tongue cancer

\begin{tabular}{|c|c|c|c|c|c|}
\hline \multirow[t]{2}{*}{ Variables } & \multirow{2}{*}{$\begin{array}{l}5 \text {-year survival } \\
\text { rate (\%) }\end{array}$} & \multicolumn{2}{|c|}{ Univariate analysis } & \multicolumn{2}{|c|}{ Multivariate analysis } \\
\hline & & Log rank $\chi^{2}$ test & $P$-value & HR (95\% Cl) & $P$-value \\
\hline Year of diagnosis & & 10.906 & 0.001 & & \\
\hline $2005-2006$ & 52.0 & & & I & \\
\hline $2007-2008$ & 55.0 & & & $0.879(0.823-0.939)$ & $<0.001$ \\
\hline Marital status & & 295.969 & $<0.001$ & & \\
\hline Not married & 42.7 & & & 1 & \\
\hline Married & 61.2 & & & $0.603(0.564-0.645)$ & $<0.001$ \\
\hline Sex & & 0.712 & 0.399 & & \\
\hline Male & 53.5 & & & 1 & \\
\hline Female & 53.8 & & & $1.006(0.934-1.084)$ & 0.874 \\
\hline Race & & 161.453 & $<0.001$ & & \\
\hline White & 55.1 & & & 1 & \\
\hline Black & 31.3 & & & $1.466(1.309-1.641)$ & $<0.001$ \\
\hline Other & 57.5 & & & $1.017(0.878-1.179)$ & 0.820 \\
\hline Age (years) & & 155.306 & $<0.001$ & & \\
\hline$\leq 50$ & 67.8 & & & I & \\
\hline$>50$ & 50.4 & & & $1.712(1.550-1.890)$ & $<0.00 \mathrm{I}$ \\
\hline Summary stage 2000 (1998+) & & 542.552 & $<0.001$ & & \\
\hline Distant & 30.4 & & & 1 & \\
\hline Regional & 52.8 & & & $0.547(0.503-0.595)$ & $<0.001$ \\
\hline Localized & 64.4 & & & $0.349(0.316-0.384)$ & $<0.001$ \\
\hline
\end{tabular}

(Continued) 
Table 2 (Continued)

\begin{tabular}{|c|c|c|c|c|c|}
\hline \multirow[t]{2}{*}{ Variables } & \multirow{2}{*}{$\begin{array}{l}5 \text {-year survival } \\
\text { rate (\%) }\end{array}$} & \multicolumn{2}{|c|}{ Univariate analysis } & \multicolumn{2}{|c|}{ Multivariate analysis } \\
\hline & & Log rank $\chi^{2}$ test & $P$-value & HR (95\% Cl) & $P$-value \\
\hline First malignant primary indicator & & 128.229 & $<0.00 \mathrm{I}$ & & \\
\hline No & 40.7 & & & 1 & \\
\hline Yes & 56.6 & & & $0.636(0.588-0.687)$ & $<0.001$ \\
\hline Grade & & 353.571 & $<0.001$ & & \\
\hline Well differentiated & 62.3 & & & $\mathrm{I}$ & \\
\hline Moderately differentiated & 51.4 & & & $1.156(1.043-1.28 I)$ & 0.06 \\
\hline Poorly differentiated & 52.6 & & & 1.021 (0.9II-I.143) & 0.725 \\
\hline Undifferentiated & 62.6 & & & $0.849(0.566-1.272)$ & 0.427 \\
\hline Surgery related radiotherapy & & 14.544 & $<0.001$ & & \\
\hline Surgery + radiotherapy & 56.0 & & & I & \\
\hline Surgery only total & 52.5 & & & $1.216(1.129-1.310)$ & $<0.001$ \\
\hline
\end{tabular}

Abbreviations: HR, hazard ratio; SEER, Surveillance, Epidemiology, and End Results.

Table 3 Univariate and multivariate analysis of radiation on tongue cancer overall survival based on different cancer stages

\begin{tabular}{|c|c|c|}
\hline \multirow[t]{2}{*}{ Variables } & \multicolumn{2}{|c|}{ Multivariate analysis } \\
\hline & HR (95\% Cl) & $P$-value \\
\hline \multicolumn{3}{|l|}{ Year of diagnosis } \\
\hline $2005-2006$ & 1 & \\
\hline $2007-2008$ & $0.907(0.802-1.025)$ & 0.118 \\
\hline \multicolumn{3}{|l|}{ Marital status } \\
\hline Not married & 1 & \\
\hline Married & $0.664(0.587-0.75 \mathrm{I})$ & $<0.001$ \\
\hline \multicolumn{3}{|l|}{ Sex } \\
\hline Male & 1 & \\
\hline Female & $1.239(1.084-1.416)$ & 0.002 \\
\hline \multicolumn{3}{|l|}{ Race } \\
\hline White & 1 & \\
\hline Black & $1.456(1.140-1.86 \mid)$ & 0.003 \\
\hline Other & $1.248(0.97 I-I .605)$ & 0.084 \\
\hline \multicolumn{3}{|l|}{ Age (years) } \\
\hline$\leq 50$ & 1 & \\
\hline$>50$ & $1.364(1.165-1.597)$ & $<0.001$ \\
\hline \multicolumn{3}{|l|}{ Summary stage 2000 (1998+) } \\
\hline Distant & 1 & \\
\hline Regional & $0.539(0.463-0.626)$ & $<0.001$ \\
\hline Localized & $0.486(0.40 \mathrm{I}-0.590)$ & $<0.001$ \\
\hline \multicolumn{3}{|c|}{ First malignant primary indicator } \\
\hline No & 1 & \\
\hline Yes & $0.666(0.566-0.784)$ & $<0.001$ \\
\hline \multicolumn{3}{|l|}{ Grade } \\
\hline Well differentiated & I & \\
\hline Moderately differentiated & $0.949(0.769-I .17 I)$ & 0.625 \\
\hline Poorly differentiated & $0.760(0.608-0.948)$ & 0.015 \\
\hline Undifferentiated & $0.535(0.270-1.06 I)$ & 0.073 \\
\hline
\end{tabular}

Abbreviation: HR, hazard ratio. by both radiotherapy and surgery. It was also found that grade was not a risk factor for patients with tongue cancer.

This was a retrospective study with several research data limitations. To improve the therapeutic effects of tongue cancer, a combined treatment consisting of surgery, radiotherapy, and chemotherapy has yet to be performed. Multicenter prospective studies are expected to be conducted in the future, in the hope of discovering better therapy options.

\section{Acknowledgment}

The authors are grateful to Dr Bendross, for his extensive support throughout article process, which has obviously improved the quality of the manuscript.

\section{Disclosure}

The authors report no conflicts of interest in this work.

\section{References}

1. Tang ZY. Modern Oncology. 2nd ed. Shanghai: Shanghai Medical University Press; 2000:988-990.

2. Gokavarapu S, Parvataneni N, Rao S LM, Reddy R, Raju KV, Chander R. Role of postoperative radiation therapy (PORT) in pT1-T2 N0 deep tongue cancers. Oral Surg Oral Med Oral Pathol Oral Radiol. 2015; 120(6): e227-e231.

3. Suzuki M, Yoshino K, Fujii T, et al. Outcome of tongue cancer treated with surgery and postoperative radiotherapy. Nihon Jibiinkoka Gakkai Kaiho. 2014;117(7):907-913.

4. Franceschi D, Gupta R, Spiro RH, Shah JP. Improved survival in the treatment of squamous carcinoma of the oral tongue. Am J Surg. 1993; 166(4):360-365.

5. Haddadin KJ, Soutar DS, Oliver RJ, Webster MH, Robertson AG, Macdonald DG. Improved survival for patients with clinically T1/T2, N0 tongue tumors undergoing a prophylactic neck dissection. Head Neck. 1999;21(6):517-525.

6. Yoshimura R, Shibuya H, Miura M, et al. Quality of Life of Oral Cancer Patients After Low-Dose-Rate Interstitial Brachytherapy. Int J Radiat Oncol Biol Phys. 2009;73(3):772-778. 
7. Maochang Y, Luo YX, Zhou RJ. The curative effect of the comprehensive treatment of tongue cancer. Oral medicine. 1991;11(2):79-81.

8. Leung T-W, Wong VYW, Wong C-M, et al. High dose rate brachytherapy for carcinoma of the oral tongue. Int J Radiat Oncol Biol Phys. 1997; 39(5):1113-1120.

9. Huan XL, Liu TF. The analysis of the long-term effects of lepidoblastoma. Radiation oncology in China. 1991;5(4):206-208.
10. Cunningham MJ, Johnson JT, Myers EN, Schramm VL, Thearle PB. Cervical lymph node metastasis after local excision of early squamous cell carcinoma of the oral cavity. Am J Surg. 1986;152(4):361-366.

11. Yamazaki $\mathrm{H}$, Inoue $\mathrm{T}$, Yoshida $\mathrm{K}$, et al. Comparison of three major radioactive sources for brachytherapy used in the treatment of node negative T1-T3 oral tongue cancer: influence of age on outcome. Anticancer Res. 2007;27(1B):491-497.

\section{Publish your work in this journal}

OncoTargets and Therapy is an international, peer-reviewed, open access journal focusing on the pathological basis of all cancers, potential targets for therapy and treatment protocols employed to improve the management of cancer patients. The journal also focuses on the impact of management programs and new therapeutic agents and protocols on

\section{Dovepress}

patient perspectives such as quality of life, adherence and satisfaction The manuscript management system is completely online and includes a very quick and fair peer-review system, which is all easy to use. Visit http://www.dovepress.com/testimonials.php to read real quotes from published authors. 